\title{
Maternal obesity and its relation with the cesarean section: A hospital based cross sectional study in Iraq
}

Waqar Al-Kubaisy ${ }^{1,3}$, Mazin Al-Rubaey ${ }^{2 *}$, Redhwan A Al-Naggar ${ }^{1,3}$, Ban Karim² and Nor Aini Mohd Noor ${ }^{1,4}$

\begin{abstract}
Background: Obesity during pregnancy is reported in approximately one in five pregnant women worldwide. It increases the risk of pregnancy complications many of which necessitate Cesarean section (CS). This study determines the association between obesity and type of delivery.

Methods: A cross-sectional study involving 404 pregnant women was carried out at Al-Yarmouk Teaching Hospital, Baghdad, Iraq. Women with hypertension, diabetes, preterm labor, fetal presentation other than cephalic presentation and multiple gestations were excluded from the study. BMI and past obstetric history were recorded.

Results: The overall rate of CS was 38\%. The overall mean body mass index (BMI) was $25.0 \pm 4.52 \mathrm{Kg} / \mathrm{m}^{2}$ and it was significantly higher among women who delivered by cesarean section. Significantly high rate of CS was found in primigravida and multigravida women with high BMI. Moreover, all obese multigravid women with history of previous CS were delivered by CS. The rate of CS was higher in women with primary level education when compared to women with secondary or tertiary education. CS was significantly lower in women with a previous history of abortion.

Conclusion: Obese women with or without a previous history of CS are at a higher risk of having a CS and should therefore be considered as high risk and managed appropriately during pregnancy. Weight management prior to or during pregnancy could help reduce the need for CS.
\end{abstract}

Keywords: Obesity, Cesarean section, Route of delivery, Iraq

\section{Background}

Obesity is most commonly measured as a weight to height ratio and expressed as body mass index (BMI) [1]. It is an internationally accepted method that provides a reliable way to assess obesity related health problems. The prevalence of obesity in adults is increasing worldwide, particularly among women of child bearing age. In Iraq, according to the Ministry of Health report the prevalence of obesity in women in reproductive age was 38.2\% in 2006 [2]. Moreover in Baghdad between 1997 and 2007 the prevalence of obesity among women in reproductive age increased from 23.6 to $25 \%[3,4]$. Globally the prevalence of maternal obesity has also

\footnotetext{
* Correspondence: maziniraq2003@gmail.com

${ }^{2}$ Community Medicine Department, Faculty of Medicine, AL-Mustanseryah University, Baghdad, Iraq

Full list of author information is available at the end of the article
}

increased, rising from 9-10\% in the early 1990's to 16 $19 \%$ in the year 2000 [5-7]. In Dublin, 19\% of women in their $1^{\text {st }}$ trimester were obese [8]. Similarly in US, obesity among pregnant women ranged from $18.5-38.3 \%$ [9]. Maternal obesity is defined as women who have a BMI $\geq 30$ $\mathrm{Kg} / \mathrm{m}^{2}$ at first antenatal visit [5]. It is calculated by dividing pre-pregnancy weight in kilograms $(\mathrm{Kg})$ by height in meter square $\left(\mathrm{m}^{2}\right)$ [6]. It is evident that obesity increases the risk of pregnancy complications. In obese mothers, the perinatal morbidity such as pre-eclampsia and gestational diabetes is high [10-12]. Obesity is associated with increased rates of cesarean section (CS) [12]. Several recent reports document rates of CS 32\% in USA [10], 19.1\% in Saudi Arabia [11], 9.29\% in Jordan [13] and 20.1\% in Iraq [14]. Interestingly also the rates of CS in Baghdad city were 17.9, 19 and 28.7\% in 2007, 2009 and 2011; respectively [15,16]. 
Table 1 Characteristic profile of Iraqi pregnant women based on the mode of delivery $(n=404)$

\begin{tabular}{|c|c|c|c|c|c|c|c|c|}
\hline \multirow[t]{2}{*}{ Variable } & \multicolumn{2}{|c|}{ Total } & \multicolumn{2}{|c|}{ NVD } & \multicolumn{2}{|c|}{ CS } & \multirow[t]{2}{*}{$x^{2}$} & \multirow[t]{2}{*}{$P$ value } \\
\hline & No & $\%$ & No & $\%$ & No & $\%$ & & \\
\hline \multicolumn{9}{|l|}{ Age (years) } \\
\hline$<20$ & 50 & 12.4 & 30 & 60.0 & 20 & 40.0 & \multirow[t]{5}{*}{4.661} & \multirow[t]{5}{*}{0.324} \\
\hline $20-24$ & 134 & 33.2 & 83 & 61.9 & 51 & 38.1 & & \\
\hline $25-29$ & 100 & 24.8 & 67 & 67.0 & 33 & 33.0 & & \\
\hline $30-34$ & 82 & 20.3 & 52 & 63.4 & 30 & 36.6 & & \\
\hline$\geq 35$ & 38 & 9.4 & 18 & 47.4 & 20 & 52.6 & & \\
\hline \multicolumn{9}{|l|}{ Husband occupation } \\
\hline Non-governmental & 238 & 58.2 & 141 & 59.2 & 97 & 40.8 & \multirow{2}{*}{1.17} & \multirow{2}{*}{0.191} \\
\hline Governmental & 166 & 41.1 & 109 & 65.7 & 57 & 34.3 & & \\
\hline \multicolumn{9}{|l|}{ Women's level of education } \\
\hline Less than Secondary & 274 & 67.8 & 160 & 58.4 & 114 & 41.6 & \multirow{2}{*}{4.39} & \multirow{2}{*}{0.036} \\
\hline Secondary and higher & 130 & 32.2 & 90 & 69.2 & 40 & 30.8 & & \\
\hline \multicolumn{9}{|l|}{ History of Abortion } \\
\hline No & 373 & 92.3 & 225 & 60.3 & 148 & 39.7 & \multirow{2}{*}{4.19} & \multirow{2}{*}{0.04} \\
\hline Yes & 31 & 7.7 & 25 & 80.6 & 6 & 19.4 & & \\
\hline \multicolumn{9}{|c|}{ Pregnant women classifications } \\
\hline Primigravida & 149 & 36.9 & 95 & 63.8 & 54 & 36.2 & \multirow{3}{*}{28.9} & \multirow{3}{*}{$<0.001$} \\
\hline Multigravida without CS & 149 & 36.9 & 111 & 74.5 & 38 & 25.5 & & \\
\hline Multigravida with CS & 106 & 26.2 & 44 & 41.5 & 62 & 58.5 & & \\
\hline
\end{tabular}

Dietz et al. (2005) showed that the rate of cesarean section was $14.3 \%$ in lean gravid women and $42.6 \%$ in obese women [17]. A linear relationship between BMI and cesarean delivery has been reported [18]. Obese women were 6 times more likely to have cesarean section due to cephalo-pelvic disproportion or failure to progress than non-obese women [19].

Earlier studies in Iraq have not evaluated the association of maternal obesity with other factors like parity and previous cesarean section, which are known risk factors for cesarean section. Therefore, the aim of this study was to determine the association of increased BMI among primigravid, multigravida with and without history of CS with the mode of delivery in the current pregnancy.

\section{Methods}

A cross-sectional study was conducted at Obstetrics Department of Al-Yarmouk Teaching Hospital, Baghdad, Iraq from January to May 2012. Ethical approval was obtained from the Ethics Committee at Ministry of Health, Baghdad, Iraq. A convenience sample of 404 pregnant women attending the labor room with induced or spontaneous labor was collected. Informed consent was obtained from each participant. The inclusion criteria were women with normal pregnancy (no pathological conditions) at $\geq$ 37 weeks of gestation. Primigravida and multigravida with normal pregnancy and live cephalic singleton fetuses were included. Pregnant women with elective cesarean section, hypertension, and diabetes were excluded. In addition,

Table 2 Mean BMI of 404 Iraqi pregnant women in relation to route of delivery

\begin{tabular}{llll}
\hline Variable & No & Mean \pm SD & Test of significance \\
\hline All women & 404 & $25.05 \pm 4.25$ & \\
Primigravidae & 149 & $24.31 \pm 4.41$ & $\mathrm{P}$ value \\
Multigravidae without CS & 149 & $25.27 \pm 4.67$ & \\
Multigravidae with CS & 106 & $25.77 \pm 4.34$ & \\
Current pregnancy with & & & \\
NVD & & $22.85 \pm 2.82$ & $Z 29$ \\
CS & & $28.62 \pm 4.49$ & $<0.048$ \\
\hline
\end{tabular}


Table 3 Mode of delivery of Iraqi pregnant women and BMI $(n=404)$

\begin{tabular}{|c|c|c|c|c|c|c|c|c|}
\hline \multirow[t]{2}{*}{ Variable } & \multicolumn{2}{|c|}{ Total } & \multicolumn{2}{|c|}{ NVD } & \multicolumn{2}{|c|}{ CS } & \multirow[t]{2}{*}{$x^{2}$} & \multirow[t]{2}{*}{$P$ value } \\
\hline & $\mathbf{N}$ & $\%$ & $\mathrm{~N}$ & $\%$ & $\bar{N}$ & $\%$ & & \\
\hline \multicolumn{9}{|l|}{ BMI } \\
\hline Underweight $(<18.5)$ & 15 & 3.7 & 13 & 86.7 & 2 & 13.3 & \multirow{4}{*}{180.1} & \multirow{4}{*}{$<0.001$} \\
\hline Normal weight (18.5-24.9) & 206 & 51.0 & 187 & 90.8 & 19 & 9.2 & & \\
\hline Overweight (25-29.9) & 116 & 28.7 & 42 & 36.2 & 74 & 63.8 & & \\
\hline Obese $(\geq 30)$ & 67 & 16.6 & 8 & 11.9 & 59 & 88.1 & & \\
\hline
\end{tabular}

multiple gestations, and abnormal lie fetus at time of labor were also excluded. Each participant was interviewed using a well constructed questionnaire. The questionnaire include socio-demographic (age, education and husband's occupation) and obstetrical (parity, history of abortion, type of previous delivery) information. In addition, height and weight were measured and the pre-pregnancy weight was calculated by subtracting $12.5 \mathrm{Kg}$ from the current weight. The average weight gain during pregnancy is estimated as $12.5 \mathrm{Kg}$ [5]. Statistical analysis was done using tests contained in SPSS 20. Descriptive data are presented in frequencies, simple percentages. Chi-square $\left(\mathrm{x}^{2}\right)$ test was used to evaluate the associations between categorical variables. ANOVA was used to test the significance of differences between more than two means and $\mathrm{Z}$ test was used to test the significance of difference of two means. A p-value of $<$ 0.05 was considered significant.

\section{Results}

A total of 404 women were included in this study. More than half of them (58\%) were $20-30$ years old and more than two thirds (68\%) had less than secondary school education. Out of 404 women 154 (38.2\%) their current pregnancy were ended by CS. Significant association between mother's education and type of delivery $(\mathrm{p}=0.036)$ was present. Women with lower primary education had significantly higher rate of CS (41.6\%) than those with secondary school and above education $(30.8 \%)(p=0.036)$. Women with history of previous abortion showed significantly lower rate of CS compared to women with no history of abortion $(p=0.04)$. However, this study showed that the mode of delivery was neither associated with the age of the women nor with the occupation of the husband $(\mathrm{p}=0.324, \mathrm{p}=0.191$; respectively). Regarding the relationship between gravidity of the mother and mode of delivery, multigravidae with previous history of CS had a significantly higher rate of CS (58.5\%) in the current pregnancy when compared to other two groups $(\mathrm{p}<0.001)$ (Table 1). The overall mean BMI in the study subjects was $25.05 \pm 4.25 \mathrm{~kg} / \mathrm{m}^{2}$ (ranging from 16.2 to 39.1 ) (Table 2). More than half (51\%) of the participants were within the normal range of BMI. However, $45.3 \%$ were overweight and obese (Table 3). Significant variation in mean BMI was detected among mothers with different gravidity (Table 2). The highest mean BMI was among the multigravidae with a previous history of CS $(25.77 \pm 4.34$ $\mathrm{Kg} / \mathrm{m}^{2}$ ), while primigravidae had the lowest mean BMI $(24.31 \pm 4.41 ; \mathrm{p}=0.029)$ (Table 2$)$. Studying the relationship between mode of delivery in the current pregnancy and BMI level, we gave an evidence that pregnant women whom their pregnancy ended by CS, their BMI was $(28.62 \pm 4.49)$ significantly higher $(\mathrm{p}<0.001)$ than $(22.85 \pm$ 2.82 ) those whom delivered normally (Table 2 ). Moreover, with increasing BMI $(\geq 25)$ above normal, CS was significantly increased steadily $(\mathrm{p}<0.001)$ (Table 3$)$. All obese $(\mathrm{BMI} \geq 30)$ multigravidae with a previous history of CS were delivered via CS. CS for the current pregnancy was significantly higher among obese $(\mathrm{BMI} \geq 30)$ primi and multigravida women without previous history of CS $(85.7 \%$ and $78.3 \%$ respectively; $\mathrm{p}<0.001)$ compared to non-obese primagravidae and multigravidae $(28.1 \%$ and $15.9 \%$, respectively) (Table 4 ).

\section{Discussion}

In this study many factors "for example diabetes mellitus, hypertension, fetal presentation other than cephalic and multiple pregnancies" that may relate to CS were excluded. In spite of that, the rate of CS delivery was higher than $(22.6 \%, 33.3 \%)$ that reported previously in Iraq [16,20], Saudi Arabia [11], Jordan [13], USA [10] and Pakistan, where it was reported as $32.3 \%$ [21]. Moreover, mean BMI of the pregnant women who delivered via

Table 4 Gravidity and mode of delivery based on BMI $(n=404)$

\begin{tabular}{|c|c|c|c|c|c|c|}
\hline \multirow[t]{2}{*}{ Gravidity } & \multicolumn{2}{|c|}{$\mathrm{BMI}<30$} & \multicolumn{2}{|c|}{$\mathrm{BMI} \geq 30$} & \multirow[t]{2}{*}{$x^{2}$} & \multirow[t]{2}{*}{$p$ value } \\
\hline & NVD & CS & NVD & CS & & \\
\hline Primi gravid & $92(71.9 \%)$ & $36(28.1 \%)$ & $3(14.3 \%)$ & $18(85.7 \%)$ & 25.89 & $<0.001$ \\
\hline Multigravida without CS & $106(84.1 \%)$ & $20(15.9 \%)$ & $5(21.7 \%)$ & $18(78.3 \%)$ & 39.85 & $<0.001$ \\
\hline Multigravida with CS & $44(53 \%)$ & $39(47 \%)$ & 0 & $23(100)$ & & \\
\hline
\end{tabular}


cesarean section was significantly higher than those via vaginal delivery. In addition, there was a significant positive association between BMI and the rate of CS. As BMI increased the rate of CS too increased, suggests that the high rate of CS in our study is mostly due to the high BMI of these women. Our finding is in agreement with Kominarek's et al., (2010) in US [22] who found that cesarean deliveries increased significantly across the different classes of obesity. Similarly, Tosson and Alhussaini in Egypt, (2005) [23] as well as Perlow et al., (1992) [24] suggested that BMI was significantly related to the mode of delivery. Cnattingham et al., (1998) in reported that obese women due to their large body volume, more time may be taken for oxytocin to reach the optimal tissue level [25]. Also presence of excess intra abdominal adipose tissue itself could mechanically obstruct the progression of labor, this could, overtime, compromise fetoplacental circulation and cause fetal distress and necessitating CS. Although higher rate of CS was found among women aged 35 years and above, this finding was however not significant, which is in contrast to the findings of Perlow et al., (1992) [24].

Our findings are also in agreement with an earlier study [26], where it was reported that women with high BMI and previous history of CS are less likely to have normal vaginal delivery during the next pregnancy. In this study it was noted that none of those obese $(\mathrm{BMI} \geq 30)$ women with a previous history of CS had ended by normal vaginal delivery. Moreover, a significantly high proportion of obese $(B M I \geq 30)$ primigravida or multi gravidae with no history of $\mathrm{CS}$ in this study had their current pregnancy ended by CS. The significantly higher rate of cesarean section among women with lower educational level supports the findings of another study in Baghdad [27]. The possible explanation is that the women with higher education are more likely to take care of their weight and body shape and practice a healthy lifestyle such as regular exercise and healthy diet. Another explanation is that low educational level may lead to poor utilization of health services during pregnancy.

\section{Conclusion}

This study showed a significant association between BMI and increased risk of cesarean delivery. Obese women should therefore be considered as high risk and managed appropriately during pregnancy. Weight management should be implemented in the primary care clinics to counsel women to reduce their weight.

\section{Competing interests}

The authors declare that they have no competing interests.

\section{Authors' contribution}

WA study design and writing the manuscript. MA study design, obtaining ethical approval from Ministry of Health, Iraq, data collection and writing the manuscript, RA statistical data analysis and writing the manuscript. BK data collection. NA agreed to be accountable in all aspects of the work, data interpretation, critical revision of the manuscript, final approval and final editing. All authors read and approved the final manuscript.

\section{Acknowledgements}

The authors would like to thank the Obstetrics Department staff at Al-Yarmouk Teaching Hospital for their support. We extend our thanks to all women who participated in this study.

\section{Financial disclosure statement}

No funding.

\section{Author details}

${ }^{1}$ Population Health and Preventive Medicine Department, Faculty of Medicine, Universiti Teknologi MARA (UiTM), Selangor, Malaysia. ${ }^{2}$ Community Medicine Department, Faculty of Medicine, AL-Mustanseryah University, Baghdad, Iraq. ${ }^{3}$ Drug Discovery \& Health Community of Research, Universiti teknologi MARA (UiTM), 40450 Shah Alam, Selangor, Darul Ehsan, Malaysia. ${ }^{4}$ Humanity and Quality of life, Universiti teknologi MARA (UiTM), 40450 Shah Alam, Selangor, Darul Ehsan, Malaysia.

Received: 31 December 2013 Accepted: 4 July 2014

Published: 17 July 2014

\section{References}

1. Gray DS, Fujioka K: Use of relative weight and body mass index for the determination of adiposity. J Clin Epidemiol 1991, 44(6):545-550.

2. Ministry of Health, Iraqi: Chronic Non-Communicable Disease Risk Factors Survey in Iraq, A STEP Wise Approach .Ministry of Health, Directorate of Public Health, Ministry of Planning and Developmental Cooperation, Central Organization for Statistics \&lnformation Technology; 2006.

3. Al-Twail NG, Abdulla NM, Abdul Ameer AJ: Prevalence of and factors associated with overweight and obesity among a group of Iraqi women. Eastern Mediterranean Health Journal 2007, 13(2):14. 50-55.

4. Swidan A: Nutritional status assessment of female 10-60 years, Household survey. Baghdad, General Federation of Iraqi women; 1997.

5. Davies GA, Maxwell C, McLeod L, Gagnon R, Basso M, Bos H, Delisle MF, Farine D, Hudon L, Menticoglou S, Mundle W, Murphy-Kaulbeck L, Ouellet A, Pressey T, Roggensack A, Leduc D, Ballerman C, Biringer A, Duperron L, Jones D, Lee LS, Shepherd D, Wilson K: SOGC clinical practice guidelines: obesity in pregnancy. Int J Gyn Obstet 2010, 110(2):167-173.

6. WHO: Obesity: Preventing and managing the global epidemic. Geneva: World Health Organization; 2000.

7. WHO: Obesity, Preventing and managing the global epidemic. In Report of WHO Consultation Obesity. WHO-Technical Report, 2000; N: 894. http:// www.who.int/dietphysicalactivity/publications/facts/obesity/en/. Accessed in January 10, 2013

8. Fattah C, Farah N, Barry S, O'conner N, Stuart B, Turner M: Maternal weight and body composition in the first trimester of pregnancy. Acta Obest and Gynecol Scand 2010, 89:952-955.

9. Galtier- Dereure F, Boenger C, Bringer J: Obesity and pregnancy: Complication and Cost. Am J Clin Nutr 2000, 71((suppl):1245-1285.

10. Hamilton BE, Martin JA, Ventura SJ: Births: Preliminary data for 2007. National Vital Statistics reports, U.S. Department of Health and Human services. Hyattsville, MD: National Center for Health Statistics; 2009. 57 (12).

11. Ba'qeel HS: King Abdulaziz medical centre: cesarean delivery. Ann- Saudi Med 2009, 29(3):179-183.

12. Reece EA: Perspectives on obesity, pregnancy and birth outcomes in the United States: The scope of the problem. Am J Obestet Gynecol 2008, 198:23-27.

13. Hindawi IM, Meri ZB: Cesarean Section Rate in Jordan. Saudi Med 2004 25(11):1631-1635.

14. Ministry of Health: Multiple Indicator Cluster Survey Final Report, Iraq 2006 ( MICS 3), Central Organization for Statistics \& Information Technology, Kurdistan Regional Office. Iraq: United Nations Children Fund; 2007.

15. Al-dobony SJ: Rate, Indications and risk factors of cesarean section in maternity hospital in Baghdad city, hD thesis, Iraqi Board of Medical Specialization, community medicine; 2009.

16. Ministry of Planning: Women Integrated Social and Health Survey, Governorate Report (I-WISH 2011), Iraq, Central Statistical Organization-CSO. 2012. 
17. Dietz PM, Callaghan WM, Morrow B, Cogswell ME: Population-based assessment of the risk of primary cesarean delivery due to excess pre-pregnancy weight among nulliparous women delivering term infants. Matern Child Health J 2005, 9:237-244.

18. Barau G, Robillard PY, Hulsey TC, Dedecker F, Laffite A, Gérardin P, Kauffmann E: Linear association between maternal body mass index and risk of cesarean section in term deliveries. BJOG 2006, 113:1173-1177.

19. Young TK, Woodmansee B: Factors that are associated with cesarean delivery in a large private practice: The importance of pre-pregnancy body mass index and weight gain. Am J Obstet Gynecol 2002, 187:312-332.

20. Ministry of Health: Department of Health Vital Statistic. Iraq: Vital Statistic registry; 2009

21. Taher SH, Shabab U: Effect of obesity on Cesarean section rate. I Surg Pakistan 2005, 15(2):93-96.

22. Kominiarek MA, Vanveldhuisen $\mathrm{P}$, Hibbard J, Landy H, Haberman S, Learman L, Wilkins I, Bailit J, Branch W, Burkman R, Gonzalez-Quintero VH, Gregory K, Hatjis C, Hoffman M, Ramirez M, Reddy UM, Troendle J, Zhang J: The maternal body mass index: a strong association with delivery route. Am J Obestet Gyneco 2010, 203(3):264. E1-7.

23. Tosson MM, Alhussaini TK: The impact of maternal obesity on pregnancy outcome at Assuit University Hospital. Ass Univ Bull Env Res 2005, 8(2):1-11.

24. Perlow JH, Morgan MA, Montgomery D, Towers CV, Porto M: Perinatal outcome in pregnancy complicated by massive obesity. AJOG 1992, 167(4):958-962

25. Cnattingham R, Cnattingham S, Notzon FC: Obstacles to reducing cesarean section rates in a low cesarean setting: The effect of maternal age, height and weight. Obstet Gynecol 1998, 92:205-206.

26. Edward RK, Haresberger S, Johnson IM, Treloar RW, Cruz AC: Deciding on route of delivery for obese women with prior cesarean delivery. Am J Obeset Gynecol 2003, 189:385-390.

27. Mohammed BS: Risk factors of cesarean section in AL-Yarmouk hospital: PhD thesis, Iraqi Board of Medical Specialization, community medicine; 2006.

doi:10.1186/1471-2393-14-235

Cite this article as: Al-Kubaisy et al: Maternal obesity and its relation

with the cesarean section: A hospital based cross sectional study in Iraq. BMC Pregnancy and Childbirth 2014 14:235.

\section{Submit your next manuscript to BioMed Central and take full advantage of:}

- Convenient online submission

- Thorough peer review

- No space constraints or color figure charges

- Immediate publication on acceptance

- Inclusion in PubMed, CAS, Scopus and Google Scholar

- Research which is freely available for redistribution 